University of Nebraska - Lincoln

DigitalCommons@University of Nebraska - Lincoln

\title{
Characterization of silver nanoparticles using flow-field flow fractionation interfaced to inductively coupled plasma mass spectrometry
}

\author{
A. R. Poda \\ US Army Engineer Research and Development Center, Aimee.R.Poda@usace.army.mil
}

A. J. Bednar

US Army Engineer Research and Development Center

A. Harmon

US Army Engineer Research and Development Center

M. Hull

NanoSafe, Inc

D. M. Mitrano

Colorado School of Mines

See next page for additional authors

Follow this and additional works at: https://digitalcommons.unl.edu/usarmyresearch

Part of the Operations Research, Systems Engineering and Industrial Engineering Commons

Poda, A. R.; Bednar, A. J.; Harmon, A.; Hull, M.; Mitrano, D. M.; Ranville, J. F.; and Steevens, J., "Characterization of silver nanoparticles using flow-field flow fractionation interfaced to inductively coupled plasma mass spectrometry" (2010). US Army Research. 147.

https://digitalcommons.unl.edu/usarmyresearch/147

This Article is brought to you for free and open access by the U.S. Department of Defense at DigitalCommons@University of Nebraska - Lincoln. It has been accepted for inclusion in US Army Research by an authorized administrator of DigitalCommons@University of Nebraska - Lincoln. 


\section{Authors}

A. R. Poda, A. J. Bednar, A. Harmon, M. Hull, D. M. Mitrano, J. F. Ranville, and J. Steevens 


\title{
Characterization of silver nanoparticles using flow-field flow fractionation interfaced to inductively coupled plasma mass spectrometry
}

\author{
A.R. Poda ${ }^{\text {a,* }}$, A.J. Bednar ${ }^{\text {a }}$, A.J. Kennedy ${ }^{\text {a }}$, A. Harmon ${ }^{\text {a }}$, M. Hull ${ }^{\text {b,c }}$, D.M. Mitrano ${ }^{\text {, J.F. Ranville }}{ }^{\text {d }}$ J. Steevens $^{\text {a }}$ \\ a US Army Engineer Research and Development Center, Environmental Laboratory, 3909 Halls Ferry Rd., Vicksburg, MS 39180, USA \\ b NanoSafe, Inc., 2200 Kraft Drive, Suite 1200 I, Blacksburg, VA 24060, USA

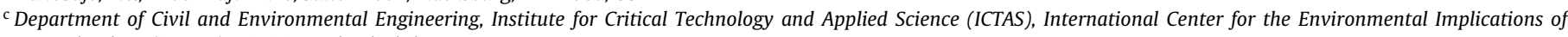 \\ Nanotechnology (iCEINT), Virginia Tech, Blacksburg, VA, USA \\ ${ }^{\mathrm{d}}$ Department of Chemistry and Geochemistry, Colorado School of Mines, Golden, CO, USA
}

\section{A R T I C L E I N F O}

\section{Article history:}

Available online $\mathrm{xxx}$

\section{Keywords:}

Nanoparticle characterization

FFF

ICP-MS

Comparison techniques

Natural matrices

\begin{abstract}
A B S T R A C T
The ability to detect and identify the physiochemical form of contaminants in the environment is important for degradation, fate and transport, and toxicity studies. This is particularly true of nanomaterials that exist as discrete particles rather than dissolved or sorbed contaminant molecules in the environment. Nanoparticles will tend to agglomerate or dissolve, based on solution chemistry, which will drastically affect their environmental properties. The current study investigates the use of field flow fractionation (FFF) interfaced to inductively coupled plasma-mass spectrometry (ICP-MS) as a sensitive and selective method for detection and characterization of silver nanoparticles. Transmission electron microscopy (TEM) is used to verify the morphology and primary particle size and size distribution of precisely engineered silver nanoparticles. Subsequently, the hydrodynamic size measurements by FFF are compared to dynamic light scattering (DLS) to verify the accuracy of the size determination. Additionally, the sensitivity of the ICP-MS detector is demonstrated by fractionation of $\mu \mathrm{g} / \mathrm{L}$ concentrations of mixed silver nanoparticle standards. The technique has been applied to nanoparticle suspensions prior to use in toxicity studies, and post-exposure biological tissue analysis. Silver nanoparticles extracted from tissues of the sediment-dwelling, freshwater oligochaete Lumbriculus variegatus increased in size from approximately $31-46 \mathrm{~nm}$, indicating a significant change in the nanoparticle characteristics during exposure.
\end{abstract}

Published by Elsevier B.V.

\section{Introduction}

Nanotechnology is a rapidly developing field, attracting significant investment from government, industry, and academia [1]. Material applications have already yielded a variety of commercially available products including cosmetics, antimicrobials, suntan lotions, paints, stain-resistant clothing and remediation products [2]. This increase in nanomaterial production poses concerns for environmental safety with the potential release of nanomaterials into the environment. Understanding the environmental behavior of nanomaterials in different environmental matrices is highly challenging. Due to their small size, nanomaterials, exhibit physiochemical properties that differ from those of other bulk materials; hence their environmental fate and effects are largely unknown.

\footnotetext{
* Corresponding author. Tel.: +1 601634 4003; fax: +1 6016342742 .

E-mail address: Aimee.R.Poda@usace.army.mil (A.R. Poda).
}

The bioavailability and potential toxicity of these materials depend on their dispersion, transport and fate through the different media encountered in the environment [3]. Nanomaterial aggregation, deposition, and dissolution behaviors factor into transport potentials and the subsequent environmental fate and ecotoxicological impacts of these materials. To quantify the stability of nanoparticles in the environment, the stability of their suspensions and their tendency to aggregate and interact with other particles must first be determined [4]. Recent reviews have touched upon the challenges associated with characterizing nanomaterials in environmental settings stressing the importance of not only the material specific properties (size, shape, and chemical composition), but also the role that surface coatings play in determining the reactivity, surface attachment and agglomeration properties of nanomaterials [5-7]. Therefore, no definitive conclusions on nanoparticle fate can be made without sufficient characterization and a quantitative understanding of nanoparticle properties in relevant environmental matrices.

A range of analytical techniques are available for providing information on concentration and particle size distributions, 
including microscopy approaches [8,9], chromatography [10,11], centrifugation [12], laser scattering [13] filtration [14-16], spectroscopic $[17,18]$ and related techniques. Generally, difficulties arise due to a lack of analytical tools capable of characterizing and quantifying particles at environmentally relevant concentrations (low $\mathrm{ppb}$ ) or in complex environmental matrices that may induce heterodisperse particle size distributions [19]. To date there have been few measurements of manufactured nanoparticles in natural waters or soils because of the extreme difficulty in detecting those at environmentally relevant concentrations $[20,21]$ while avoiding the potential interference of natural nanoparticles frequently present in environmental samples [22].

It has been reported that the average size and size distribution of nanoparticles can significantly vary when comparing results from different techniques [23]. Each technique is not without limitations and, therefore inaccurate predictions of material properties and structure can result. Correct size measurements are difficult, depending on the tool applied and the media in which the particles are dispersed. Electron microscopy (EM) and dynamic light scattering (DLS) are the most commonly used techniques. Both have advantages and disadvantages [24]. EM gives the most direct information on the size distribution and shapes of the primary particles, however there is concern about artifacts introduced by the sample preparation step attributed to the lack of a representative sample. In addition, organic coatings that are not visible in the electron microscope (due to light elements, such as carbon) can lead to discrepancies in sizing, especially when compared to sizing tools that measure the hydrodynamic diameter of particles. Dynamic light scattering (DLS) measures the particle hydrodynamic diameter, but limitations include: poor sensitivity at dilute concentrations, nonselective material detection, inability to distinguish mixtures or complex matrices and little capability to count particles to resolve the dominant size in multi-modal particle or aggregate size distributions. With DLS, the presence of a relatively small number of large aggregates will skew the effective diameter of a distribution of predominantly smaller particles toward a larger particle size distribution.

For studies of nanoparticles, field flow fractionation (FFF) has been advocated, in particular, a variation called flow field flow fractionation (FFFF) $[25,26]$. FFF is a family of separation techniques designed to separate particles based on diffusion coefficient, and when coupled to an elemental specific detector, such as ICP-MS, particle composition as a function of hydrodynamic size can be determined. This paper describes the development and application of an FFF-ICP-MS method for the characterization of silver nanoparticle mixtures. It has been applied to two types of particles known to have stable aqueous suspensions. The primary advantages over DLS and EM are demonstrated with element/particle specific detection and the ability to size particle mixtures. Furthermore, the addition of the sensitive and selective ICP-MS detector allows for determination of silver nanoparticles at environmentally relevant concentrations (low ppb). Furthermore, the technique is applied to biological media to characterize silver nanoparticles before and after exposure to the freshwater oligochaete, Lumbriculus variegatus.

\section{Materials and methods}

\subsection{Nanosilver particles}

Two sources of silver nanoparticles were investigated in the current study. Aqueous NanoXact silver nanoparticle suspensions ranging in size from 10 to $80 \mathrm{~nm}$ were supplied by Nanocomposix (San Diego, CA). These particles were generally monodisperse in size and were acquired in $10 \mathrm{~nm}$ increments ranging from 10 to
$80 \mathrm{~nm}$ as nominal $20 \mathrm{mg} / \mathrm{L}$ suspensions. The $10 \mathrm{~nm}$ silver particles were stabilized in $2 \mathrm{mM}$ citrate buffer solutions, while the particles ranging in size from 20 to $80 \mathrm{~nm}$ were stabilized in $2 \mathrm{mM}$ phosphate buffer solutions as described by the manufacturer. Secondly, a polyvinylpyrrolidone (PVP)-coated nanosilver, produced by Luna Innovations (Blacksburg, VA, USA) by reduction of $\mathrm{AgNO}_{3}$ in ethylene glycol (solvent and reducing agent) with PVP added for stabilization, was also utilized. The raw reaction product was dialyzed against water to remove ethylene glycol, unbound PVP and $\mathrm{Ag}^{+}$that may have been present.

\subsection{Transmission electron microscopy}

Transmission electron micrographs (TEM) of the dried silver NanoXact silver particles were obtained by subsampling particle suspensions (10-20 $\mu \mathrm{L}$ ) using a Zeiss 10CA TEM(Zeiss, Oberkochen, Germany) operating at $60 \mathrm{kV}$ and equipped with an AMT Advantage GR/HR-B CCD Camera digital imaging system. The longest dimension of all distinct particles ( $\geq 202$ per material analyzed) that were observed in each of 10 images was manually analyzed using ImagePro ${ }^{\circledR}$ Plus software Version 7.0 (Media Cybernetics Inc., Bethesda, MD, USA). The scale bar from the TEM images was used to calibrate the software.

\subsection{Dynamic light scattering}

Dynamic light scattering hydrodynamic size of the silver NanoXact particles was obtained using a 90 Plus/BI-MAS (Brookhaven Instruments, Holtsville, NY, USA) instrument applying a $660 \mathrm{~nm}$ laser oriented at $90^{\circ}$ relative to the sample. The software was optimized to report summary statistics based upon the intensity of light scattered. Two $\mathrm{mL}$ sample volumes from each nanosilver dispersion $(10 \mathrm{mg} / \mathrm{L}$ nominal) were loaded into glass cuvettes (supplied by manufacturer) and summary statistics were obtained using triplicate $3 \mathrm{~min}$ analyses (total analysis time $=9 \mathrm{~min}$ ). Instrument performance was verified using a polymer reference standard known to be $92 \pm 3.7 \mathrm{~nm}$ (NIST traceable diameter, Duke Scientific, 3090A, Palo Alto, CA, USA).

\section{4. $F F F-I C P-M S$}

The instrument used for all studies was an F-1000 symmetrical flow field flow fractionation (FFF) system from Postnova Analytics (Salt Lake City, UT), interfaced to a PerkinElmer Elan DRC II ICP-MS using a MiraMist pneumatic nebulizer. An Agilent 1100 variable wavelength detector was placed in-line between the FFF and ICPMS systems to collect UV absorption data, primarily for detection of polystyrene bead size standards. UV absorbance data was not collected for the dilute nanosilver particles measured due to the limited absorbance of the silver nanoparticles at the low concentrations $(\mu \mathrm{g} / \mathrm{L})$ studied. The FFF system was equipped with a $10 \mathrm{kDa}$ regenerated cellulose membrane. The mobile phase consisted of a $0.025 \%$ sodium azide and $0.025 \%$ FL-70 surfactant dissolved in deionized water with a resistivity of $18.3 \mathrm{M} \Omega \mathrm{cm}$. Separation of the particles under investigation was achieved using a channel flow of $1.0 \mathrm{~mL} / \mathrm{min}$ and a cross flow of $0.75 \mathrm{~mL} / \mathrm{min}$. The channel flow conditions allow direct connection of the FFF effluent to the ICPMS nebulizer without a flow splitter. Additional details of the FFF separation conditions are listed in Table 1.

The ICP-MS was operated in standard mode due to the lack of interferences on the 2 isotopes of silver $\left({ }^{107} \mathrm{Ag}\right.$ and $\left.{ }^{109} \mathrm{Ag}\right)$. The plasma was operated at $1250 \mathrm{~W}$ and the nebulizer flow at $0.8 \mathrm{~mL} / \mathrm{min}$. Both silver isotopes were monitored for detection and confirmation, each had an integration dwell time of $500 \mathrm{~ms}$, resulting in a data point being collected at a rate of approximately 1 per second. The number of readings per replicate was chosen such that 
Table 1

Analytical instrumentation parameters used for separation and characterization of silver nanoparticles by FFF-ICP-MS.

\begin{tabular}{ll}
\hline FFF system & Postnova F-1000 Symmetrical \\
Membrane & $10 \mathrm{kDa}$ regenerated cellulose \\
Channel and cross flow & 1.0 and $0.75 \mathrm{~mL} / \mathrm{min}$, \\
& respectively \\
Injection volume & $50 \mu \mathrm{L}$ \\
Load time & $15 \mathrm{~s}$ \\
Relaxation time & $3.2 \mathrm{~min}$ \\
Approximate fractogram time & $25 \mathrm{~min}$ \\
$\quad(100$ nm elution) & \\
UV absorbance detector & Agilent 1100 VWD \\
Wavelength monitored & $254 \mathrm{~nm}$ \\
Integration time & $0.4 \mathrm{~s}$ \\
ICP-MS & PerkinElmer Elan DRC II \\
Plasma power & $1250 \mathrm{~W}$ \\
Nebulizer, spray chamber, and & MiraMist, Double Pass Scott, \\
flow & $0.8 \mathrm{~mL} / \mathrm{min}$ \\
Masses monitored & $107 \mathrm{Ag}, 109 \mathrm{Ag}$ \\
Dwell time per AMU & $500 \mathrm{~ms}$ \\
Readings per replicate & 1600 \\
\hline
\end{tabular}

data were collected for the entire length of the fractogram, usually for about $25 \mathrm{~min}$. Table 1 also lists the operating conditions for the variable wavelength detector and ICP-MS.

\subsection{Calibration}

The theory behind FFF separation and sizing is well developed [27-29]. One of the advantages of flow FFF for particle size determination is that elution time under identical processing conditions (cross-flow and channel flow settings, carrier solution, etc.) is solely related to particle size, and follows a linear correlation [30]. In this paper, flow FFF was used to determine mean particle size as a function of fractogram elution time using NIST-traceable polystyrene bead size standards obtained from Postnova Analytics (Art. Nr. zPS-POS-000-0 (02:05:1)). A three bead mixture (20,50, and $100 \mathrm{~nm})$ was created by dilution of the single-size stock standards (1\% solids in $15 \mathrm{ml}$ ) in deionized water to a final concentration of approximately $80 \mathrm{mg} / \mathrm{L}$ for each particle size.

The fractograms of the polystyrene bead mixture shown in Fig. 1 illustrate this size-distribution of particles is well-resolved. Data from three replicate injections approximately $24 \mathrm{~h}$ apart was collected for Fig. 1 showing excellent reproducibility. The small peak at about $275 \mathrm{~s}$ is the "void peak" representing the material not retained by the field. The elution time at maximum absorbance was related to the mean particle size of the polystyrene standards. Retention time from the UV absorbance fractogram of the polystyrene standards was then used to establish a linear response function of size vs. elution time, as shown in Fig. 1 inset. Typical correlation coefficients from the three point calibration are greater than 0.9999. This linear response function was used in conjunction with the ICP-MS data to determine the mean particle size for the nanosilver examined in this study.

\subsection{Quantitative analysis}

Quantitative analyte recovery experiments designed to determine the amount of nanoparticle loss to the FFF separation system and ICP-MS sample introduction system were performed. This analysis addresses concerns over nanosilver analysis, namely loss of NPs due to adhesion to physical surfaces of the membrane, tubing and spray chamber. Recoveries of the three silver nanoparticle sizes tested $(10,40$, and $70 \mathrm{~nm})$ with the cross flow field on, cross flow field off, and bypassing the FFF entirely yielded recoveries of $88-98 \%$ based on integrated peak areas, which is deemed excellent recovery for any traditional metals analysis [31]. While some loss of particles can be expected due to interactions with the FFF membrane, minimal loss occurs to the ICP-MS sample introduction system, although only about $5-10 \%$ of the sample is actually aspirated into the plasma, due to known nebulizer efficiencies.

\subsection{Biological exposure}

A freshwater sediment (Browns Lake, Vicksburg, MS, USA) was nominally spiked at $100 \mathrm{mg} \mathrm{Ag} / \mathrm{kg}$ (measured $=70 \mathrm{mg} / \mathrm{kg}$ ) with the PVP-coated silver nanoparticle (described above) and aged for two weeks. Following the aging period, the freshwater oligochaete $L$. variegatus was exposed to the sediment for 28 days following standard method guidance [32]. Organisms were removed from the sediment, depurated as specified by method guidance [32] composited from each experimental replicate, and frozen. Prior to FFF analysis, $1.0 \mathrm{~g}$ of frozen tissue was added to $10 \mathrm{~mL}$ of deionized water and sonicated for $1 \mathrm{~h}$ and then centrifuged to remove biological debris. The supernatant was then analyzed by FFFICP-MS.

\subsection{Statistical analysis}

Data normality (Kolmogorov-Smirnov's test), homogeneity (Levene's test), and one-way ANOVA and Tukey's test were determined at the $\alpha=0.05$ level. The results from the different particle sizing techniques were compared by Pearson product moment correlation. All analyses were performed using SigmaStat Software (SSPS, Chicago, IL, USA).

\section{Results and discussion}

\subsection{Transmission electron microscopy}

The TEM images shown in Fig. 2 demonstrate the spherical shape and narrow particle size distribution of the NanoXact silver nanoparticles. Manual size analysis of the individual particles over a range of TEM magnifications is listed in Table 2. The average primary particle size is very close to the nominal size reported by the manufacturer. There is some indication that the $60 \mathrm{~nm}$ size particles are slightly larger than the reported $(67 \mathrm{~nm}$ by TEM vs. nominal $60 \mathrm{~nm}$ ), yet overall agreement within $1-5 \mathrm{~nm}$ is observed (except the $60 \mathrm{~nm}$ ) with similar size standard deviations for each particle size.

\subsection{Dynamic light scattering}

Hydrodynamic effective diameters of the particles measured by DLS are listed in Table 2. As expected, the hydrodynamic diameter is slightly larger than the primary particle size, indicative of a surface layer of the stabilizing agent and/or the hydration sphere. The DLS effective diameter ranges reported above may be indicative of some occurrence of particle aggregation in aqueous suspension. The autocorrelation function indicated acceptable data capture for all analyzed particles, the baseline index ranged from 6.0 to 9.5 (exceptions: $\mathrm{NC} 10=0 ; \mathrm{NC} 20=1.3$ ) and the data retention ranged from $93 \%$ to $100 \%$. The count rate (kcps) ranged from 136 to 490 , although substantially lower (16) for nominal $10 \mathrm{~nm}$ particles. It is noteworthy that the comparisons between TEM primary particle size, FFF and DLS are very close in this study partially due to the tight particle size distribution of the NanoXact materials. In cases where much more polydisperse primary particle (or aggregate) sizes are found in suspension [35], larger discrepancies between FFF and DLS outputs are likely to be observed due to differences in how particle sizes are determined and how summary parameters are weighted 
FFF-UV Separation of Mixed Polystyrene Bead Standards

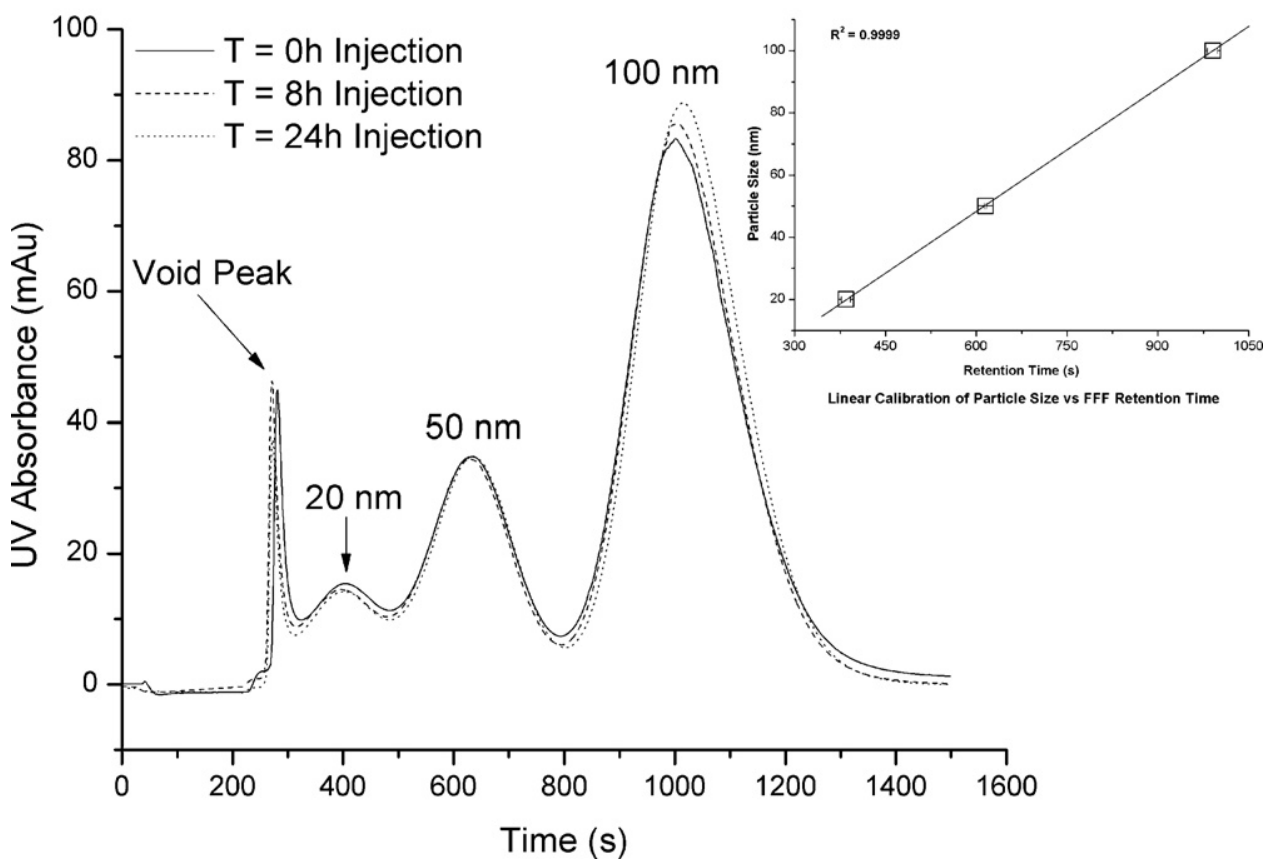

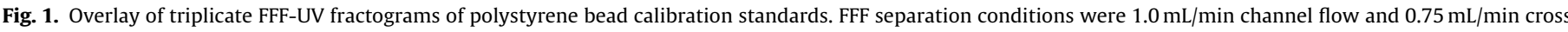

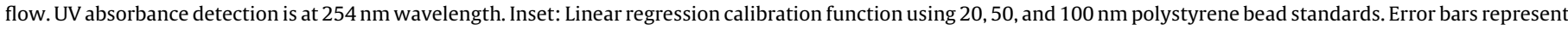
standard deviation of the triplicate retention times obtained from UV absorbance data at maximum absorbance.

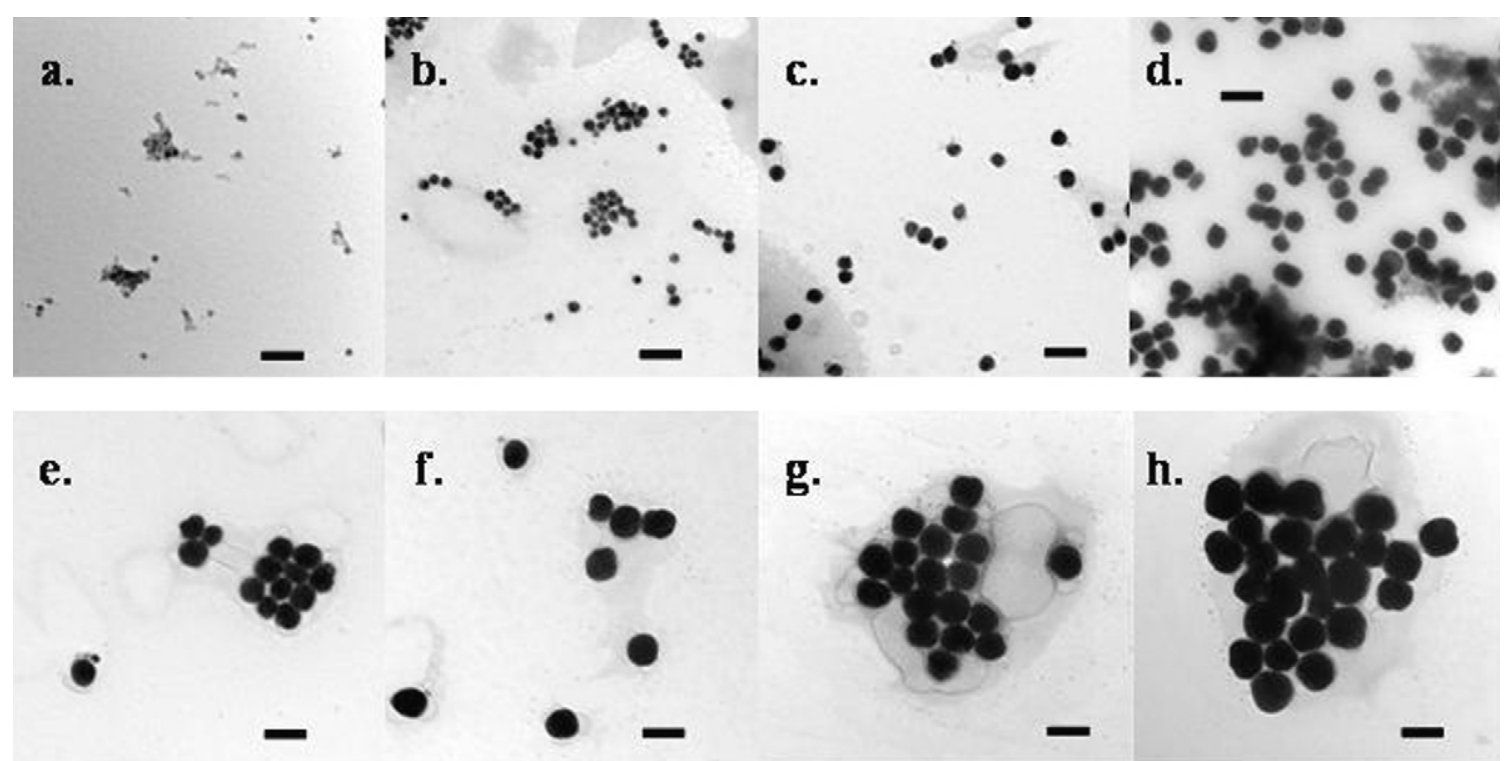

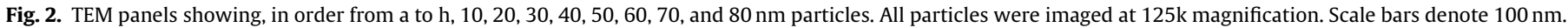

Table 2

Size determinations by three independent analytical techniques for the NanoXact silver nanoparticles. Ranges are provided in parentheses.

\begin{tabular}{|c|c|c|c|c|c|c|c|c|}
\hline & \multicolumn{8}{|l|}{ Nominal } \\
\hline & $10 \mathrm{~nm}$ & $20 \mathrm{~nm}$ & $30 \mathrm{~nm}$ & $40 \mathrm{~nm}$ & $50 \mathrm{~nm}$ & $60 \mathrm{~nm}$ & $70 \mathrm{~nm}$ & $80 \mathrm{~nm}$ \\
\hline $\begin{array}{l}\text { Mean } \mathrm{TEM} \pm \text { Std. dev. (size } \\
\text { range) }\end{array}$ & $9 \pm 1(2-20)$ & $20 \pm 1(5-33)$ & $32 \pm 4(5-48)$ & $42 \pm 4(16-60)$ & $55 \pm 5(35-74)$ & $67 \pm 4(38-88)$ & $72 \pm 3(16-89)$ & $84 \pm 5(48-112)$ \\
\hline $\begin{array}{l}\text { DLS effective diameter (size } \\
\text { range) }\end{array}$ & $22(11-84)$ & $29(13-90)$ & $41(15-124)$ & $51(35-113)$ & $54(14-121)$ & $67(32-133)$ & $74(64-104)$ & $86(58-142)$ \\
\hline $\begin{array}{l}\text { FFF-ICP-MS mean } \\
\text { hydro-dynamic diameter }\end{array}$ & 26 & 31 & 40 & 52 & 61 & 75 & 76 & 86 \\
\hline
\end{tabular}


(e.g., DLS intensity analysis is weighted toward the larger particles in the dispersion).

\subsection{FFF separation and sizing}

Size fractionation of the NanoXact particles by serial filtration was examined prior to the FFF separation method development. Serial filtration is generally an appealing approach because of its low cost and ease of use. However filtration size resolution is limited by the available filter pore sizes. Of more concern, however, is that separation results were highly variable and dependant not only on the filter pore size but also on the composition of the filtration membrane [33]. Therefore, the need to develop the FFF separation method was critical.

The overlays shown in Fig. 3 are FF fractograms of the individual NanoXact particles obtained under the standardized processing conditions (Table 1) by FFF-ICP-MS. The concentration of silver in each Injection was $200 \mu \mathrm{g} / \mathrm{L}$. The size data obtained from the FFF analysis listed in Table 2 agrees well with the DLS size results. In both cases the size measurements are slightly larger than the TEM results and are reflective of measurement techniques specific to the measurement of the hydrodynamic diameter rather than the primary particle. Under the flow conditions outlined in Table 1, baseline resolution of nanomaterials that vary in size by $10 \mathrm{~nm}$ was not obtained. However, sufficient resolution was achieved for sizing the subject particles based on maximum peak intensity. The nominal 60 and $70 \mathrm{~nm}$ particles graphed in Fig. 3 are in agreement with the DLS results with sizes reported in Table 2 that are nearly the same. This is clearly demonstrated as the fractograms nearly overlap, indicating the similar size of these two nanoparticles.

To demonstrate the separation and detection potential of the FFF-ICP-MS method more clearly, Fig. 4 shows a mixture of the nominal 10,40 , and $70 \mathrm{~nm}$ silver nanoparticles, each particle present at a total silver concentration of $67 \mu \mathrm{g} / \mathrm{L}$. The particles produced clearly defined peaks under these separation conditions, although baseline resolution was not achieved. The noise of the

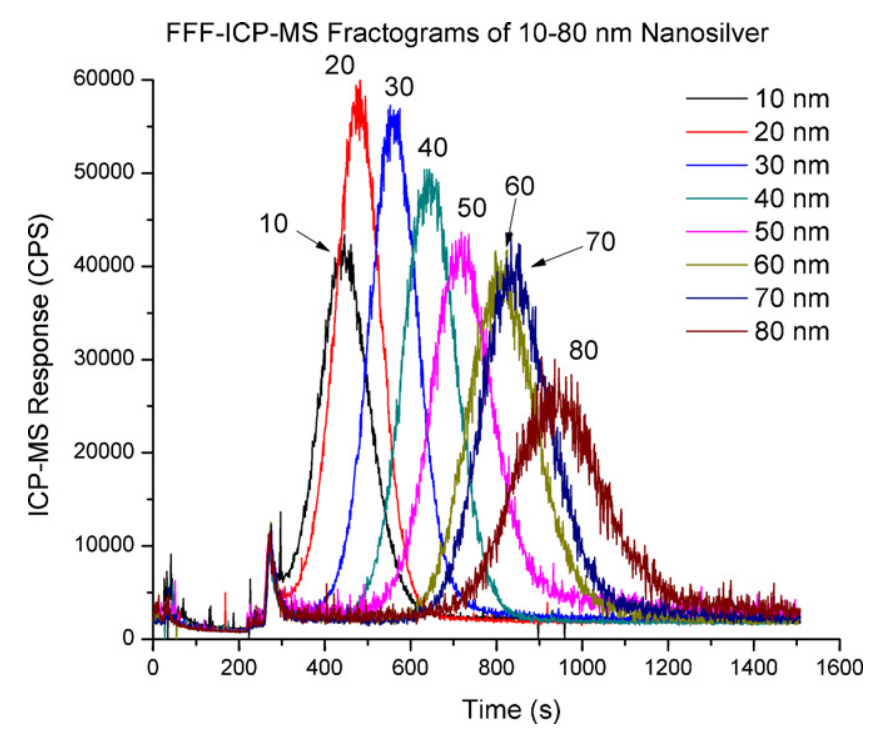

Fig. 3. Individual FFF-ICP-MS fractograms overlain of NanoXact silver nanoparticles. Each peak represents $200 \mu \mathrm{g} / \mathrm{L}$ total silver as nanosilver particles. FFF separation conditions were $1.0 \mathrm{~mL} / \mathrm{min}$ channel flow and $0.75 \mathrm{~mL} / \mathrm{min}$ cross flow with ICP-MS detection using ${ }^{107} \mathrm{Ag}$.

signals appears to increase with the nanoparticle size. It is hypothesized that the larger nanoparticles may result in more 'spikes' in the ICP-MS signal due to the delivery of larger amounts of silver into the plasma/detector system per particle unit. This phenomena is described in the use of ICP-MS as a 'single particle counter' currently being developed by several research groups [34].

Also shown in Fig. 5 is a 1:5 dilution of the $67 \mu \mathrm{g} / \mathrm{L}$ sample, which yields a total silver concentration for each particle of approximately $13.4 \mu \mathrm{g} / \mathrm{L}$. Although the fractogram peaks are quite small, they are still clearly defined at this concentration level. To further test the sensitivity of the ICP-MS detector, the inset in Fig. 5 shows a 1:10

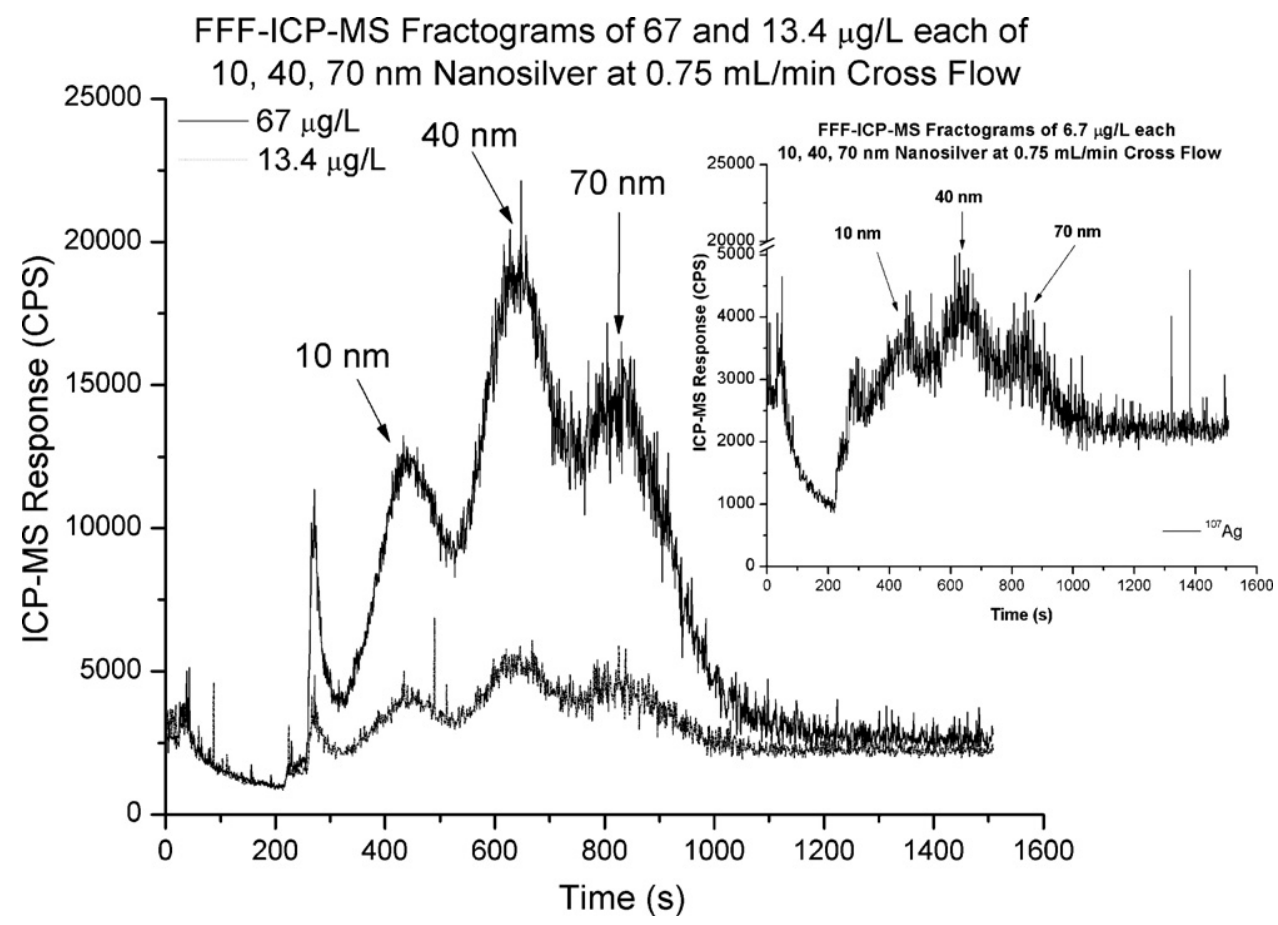

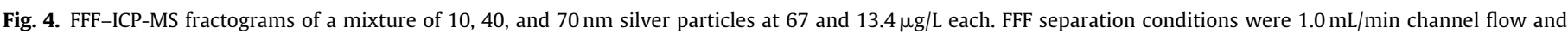

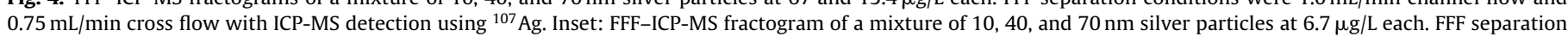
conditions were $1.0 \mathrm{~mL} / \mathrm{min}$ channel flow and $0.75 \mathrm{~mL} / \mathrm{min}$ cross flow with ICP-MS detection using ${ }^{107} \mathrm{Ag}$. 


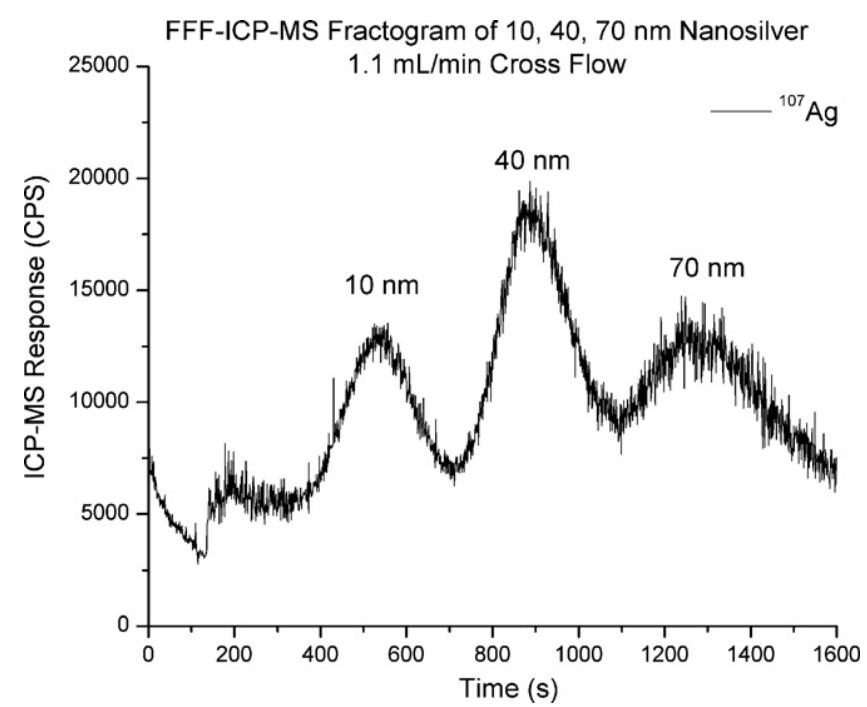

Fig. 5. FFF-ICP-MS fractogram of a mixture of 10,40 , and $70 \mathrm{~nm}$ silver particles at $67 \mu \mathrm{g} / \mathrm{L}$ each. FFF separation conditions were $1.0 \mathrm{~mL} / \mathrm{min}$ channel flow and $1.1 \mathrm{~mL} / \mathrm{min}$ cross flow with ICP-MS detection using ${ }^{107} \mathrm{Ag}$.

dilution of the $67 \mu \mathrm{g} / \mathrm{L}$ mixture, yielding a total silver concentration of $6.7 \mu \mathrm{g} / \mathrm{L}$ for each particle size. At this concentration, the ICP-MS signal is quite noisy, yet three peaks are still sufficiently defined in the fractogram to characterize the particle size, which suggests the method is applicable to detection and characterization of silver nanoparticles at concentrations less than $10 \mu \mathrm{g} / \mathrm{L}$.

Improved separation of the 10,40 , and $70 \mathrm{~nm}$ particle mixture would be ideal, therefore, as shown in Fig. 5, increasing the cross flow to $1.1 \mathrm{~mL} / \mathrm{min}$, further increases separation with minimal reduction in sensitivity and minor peak broadening. Under these flow conditions, the separation is improved with similar sensitivity, and only a minimal sacrifice in analytical time.

\subsection{Comparison of size measurements}

Pearson correlations of all of the size measurement techniques (manufacturer nominal size, TEM, DLS, FFF) resulted in very strong and significant correlations $(r>0.99 ; p<0.001)$. Comparisons of the slopes of linear regressions of the measurement techniques (Table 3) indicated that the measures of hydrodynamic diameter (DLS and FFF) had the best correlation (slope $=1.000$ ), followed by nominal size vs. TEM primary particle size $($ slope $=1.075)$ and nominal size vs. FFF (slope $=0.904)$. The smallest slope $(0.830)$ was observed for TEM primary particle size vs. DLS, which is only partially due to the relatively larger than expected effective diameter of the $10 \mathrm{~nm}$ particle (Table 2 ). This may be primarily explained by the DLS measuring of the hydrodynamic diameter of the particles, which is by definition larger than the primary particle size (note that TEM vs. FFF also results in a relatively small slope for the same reasons). This is further supported by $y$-intercepts being closest to zero for more similar measurement techniques, i.e., the measurement techniques that elucidate primary particle size (manufacturer

Table 3

Results of linear regression analysis of the different particle sizing techniques employed in this investigation.

\begin{tabular}{llcc}
\hline Methods compared & $R^{2}$ & $y$-Intercept & Slope \\
\hline Nominal vs. TEM & 0.995 & -0.75 & +1.075 \\
Nominal vs. DLS & 0.992 & +12.607 & +0.898 \\
Nominal vs. FFF & 0.985 & +15.214 & +0.904 \\
TEM vs. DLS & 0.986 & +13.458 & +0.830 \\
TEM vs. FFF & 0.992 & +15.79 & +0.842 \\
DLS vs. FFF & 0.979 & +2.891 & +1.000 \\
\hline
\end{tabular}

FFF-ICP-MS Fractogram of PVP-Nanosilver 'Standard'

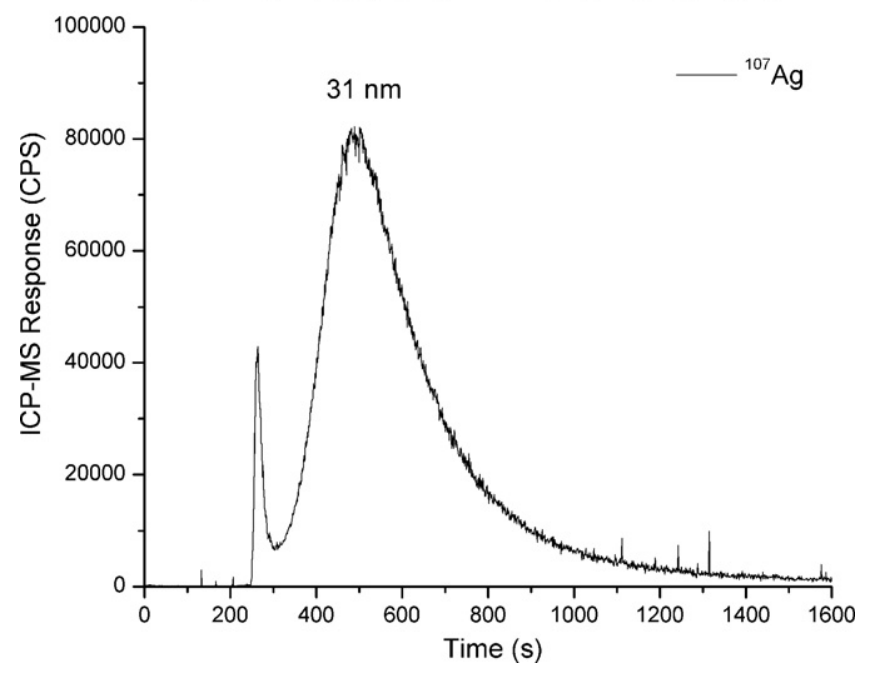

Fig. 6. FFF-ICP-MS fractogram of the stock PVP-coated silver nanoparticle in deionized water. FFF separation conditions were $1.0 \mathrm{~mL} / \mathrm{min}$ channel flow and $0.75 \mathrm{~mL} / \mathrm{min}$ cross flow with ICP-MS detection using ${ }^{107} \mathrm{Ag}$.

nominal vs. TEM primary particle size) and hydrodynamic diameter (DLS vs. FFF) had intercepts approximating zero; -0.75 and 2.891 , respectively.

\subsection{Application to biological exposures}

The above described FFF-ICP-MS technique was subsequently applied to characterization of nanoparticles after exposure to a biological receptor. Specifically, the freshwater oligochaete Lumbriculus variegates, was exposed to PVP-coated nanosilver spiked sediment as described above. In order to determine the effect of environmental exposure on the nanoparticle physiochemical form, the stock nanoparticles were first analyzed by FFF-ICP-MS, as shown in Fig. 6. Comparison to the polystyrene size calibration indicates the PVP-silver particles produce a stable dispersion and have an average hydrodynamic size of about $31 \mathrm{~nm}$.

After the 28-day biological exposure, the tissues were extracted with deionized water using sonication, with the resultant supernatant analyzed by FFF-ICP-MS, as shown in Fig. 7. The silver nanoparticles extracted from the tissue have an average hydrodynamic size of approximately $46 \mathrm{~nm}$, compared to the original $31 \mathrm{~nm}$. This size increase may indicate coating of the particles with proteins or other biological molecules. However, because no data are available on the coating from this analysis, it is possible that biological mechanisms, or abiotic reactions in the soil exposure medium, have removed the stabilizing PVP coating, resulting in aggregation of the resulting destabilized silver particles. Additional work is underway to discern the exact mechanism, yet these preliminary results demonstrate that exposure of nanoparticles to environmental media (sediment or biological) can change the particle physiochemical form and FFF-ICP-MS can be successfully used to characterize nanomaterials extracted from such complex media. Unfortunately, recovery of particle vs. total silver loading cannot be determined for the biological sample as the particles were extracted using a deionized water and sonication method, which has an unknown extraction efficiency. Total silver analysis is routinely accomplished with aggressive acid digestion methods which completely destroy the sample matrix and likely any particle-form information, resulting in a difference between particle analysis by FFF-ICP-MS and total silver analysis by digestion and ICP-MS being a result of the extraction procedures rather than the analytical techniques. 


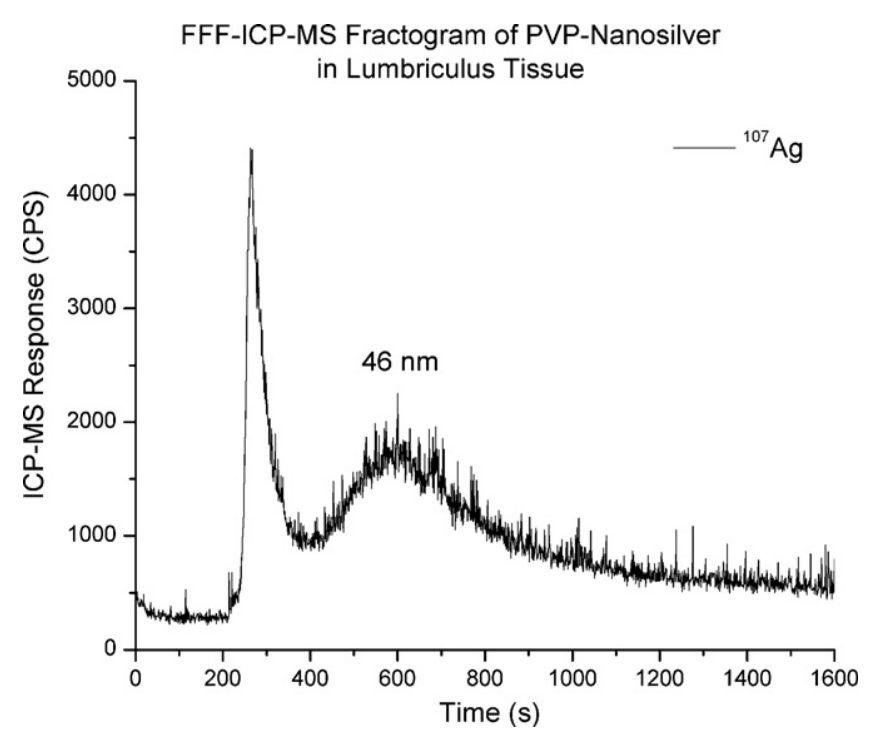

Fig. 7. FFF-ICP-MS fractogram of a PVP-coated silver nanoparticle extracted from Lumbriculus tissue by sonication in deionized water. FFF separation conditions were $1.0 \mathrm{~mL} / \mathrm{min}$ channel flow and $0.75 \mathrm{~mL} / \mathrm{min}$ cross flow with ICP-MS detection using ${ }^{107} \mathrm{Ag}$.

\section{Conclusions}

FFF-ICP-MS provides a powerful tool for nanoparticle characterization, particularly metal or metal oxide particles, due to the sensitivity and selectivity of the ICP-MS detector. However, the particles must create a stable aqueous suspension for FFF analysis. The method has been shown to produce comparable results to other established sizing methods, such as DLS, for determination of particle hydrodynamic diameter. The results are also in qualitative agreement with primary particle sizes determined by microscopy. The FFF-ICP-MS technique is applicable to environmentally relevant particle concentrations and matrices, allowing detection and characterization of nanoparticles extracted from biological receptors after exposure. The ability to discern particle size and composition at $\mu \mathrm{g} / \mathrm{L}$ concentrations further demonstrates the utility of the method for environmental applications.

\section{Acknowledgments}

The use of trade, product, or firm names in this report is for descriptive purposes only and does not imply endorsement by the U.S. Government. The tests described and the resulting data presented herein, unless otherwise noted, were obtained from research conducted under the Environmental Quality Technology Program of the United States Army Corps of Engineers by the
USAERDC. Permission was granted by the Chief of Engineers to publish this information. The findings of this report are not to be construed as an official Department of the Army position unless so designated by other authorized documents. The authors also thank Frances Hill and Gail Blaustein of the USACE for their editorial comments.

\section{References}

[1] B. Karn, T. Kuiken, T.A. Otto, Environ. Health Perspect. 117 (2009) 1823.

[2] Y. Tian, B. Gao, C. Silvera-Batista, K.J. Ziegler, J. Nanopartic. Res. (2010), doi:10.1007/s11051-010-9912-7.

[3] M.R. Wiesner, G.V. Lowry, K.L. Jones, M.F. Hochella Jr., R.T. DiGiulio, E. Casman, E.S. Bernhardt, Environ. Sci. Technol. 43 (17) (2009) 6458.

[4] C.E. Mackay, M. Johns, J.H. Salatas, B. Bessinger, M. Perri, Integr. Environ. Assess. Manage. 2 (2006) 293.

[5] B. Nowack, Environ. Pollut. 150 (1) (2007) 5.

[6] N. Saleh, K. Sirk, Y.-Q. Liu, T. Phenrat, B. Dufour, K. Matyjaszewski, R.D. Tilton, G.V. Lowry, Environ. Eng. Sci. 24 (2007) 45.

[7] H.F. Lecoanet, J.-Y. Bottero, M.R. Wiesner, Environ. Sci. Technol. 38 (2004) 5164.

[8] D. Mavrocordatos, D. Perret, J. Microsc. 191 (1998) 83.

[9] G.G. Leppard, D. Mavrocordatos, D. Perret, Water Sci. Technol. 50 (2004) 1.

[10] W.A. Scrivens, J.M. Tour, K.E. Creek, L. Pirisi, J. Am. Chem. Soc. 116 (1994) 4517.

[11] Y. Song, V. Jimenez, C. McKinney, R. Donkers, R.W. Murray, Anal. Chem. 75 (2003) 5088.

[12] D.Y. Lyon, L.K. Adams, J.C. Falkner, P.J.J. Alvarez, Environ. Sci. Technol. 40 (2006) 4360.

[13] K.W. Powers, M. Palazuelos, B.M. Moudgil, S.M. Roberts, Nanotoxicology 1 (2006) 42.

[14] A. Akthakul, A. Hochbaum, F. Stellacci, A.M. Mayes, Adv. Mater. 17 (2005) 532.

[15] K.A. Howell, E.P. Achterberg, A.D. Tappin, P.J. Worsfold, Environ. Chem. 3 (2006) 199.

[16] J. Jamison, et al., Nanotechnology 20 (2009) 355702.

[17] C.J. Powell, J. Vac. Sci. Technol. A 8 (1980) 735.

[18] J.Y. Liu, J. Electron Microsc. 54 (2005) 251

[19] A.R. Petosa, D.P. Jaisi, I.R. Quevedo, M. Elimelech, N. Turenkiji, Environ. Sci. Technol. 44 (2010) 6532.

[20] N.S. Wigginton, K.L. Haus, M.F. Hochella, J. Environ. Monit. 9 (2007) 1306.

[21] R.F. Domingos, M.A. Baalousha, Y. Ju-nam, M.M. Reid, N. Tufenkji, J.R. Lead, G.G. Leppard, K.J. Wilkinson, Environ. Sci. Technol. 43 (2009) 7277.

[22] J.R. Lead, K.J. Wilkinson, Environ. Chem. 3 (2006) 159.

[23] C.Y. Wang, et al., Meas. Sci. Technol. 18 (2007) 487.

[24] A. Bootz, V. Vogel, D. Schubert, J. Kreuter, Eur. J. Pharm. Biopharm. 57 (2004) 369.

[25] K. Tiede, A.B.A. Boxall, D. Tiede, S.P. Tear, H. David, J. Lewis, J. Anal. At. Spectrom. (2009), doi:10.1039/b822409a.

[26] M. Hassellov, J.W. Readman, J.F. Ranville, K. Tiede, Ecotoxicology 17 (2008) 344.

[27] J. Giddings, J. Chem. Phys. 49 (1968) 81.

[28] J. Giddings, K. Caldwell, Physical Methods of Chemistry, vol. IIIB, WileyInterscience, New York, 1989, pp. 120-139.

[29] M. Schimpf, Field-flow Fractionation Handbook, Wiley-Interscience, New York, 2000, pp. 71-79.

[30] S. Lee, P. Rao, S. Prabhakara, M.H. Moon, Anal. Chem. 68 (1996) 1545.

[31] S. Dubascoux, I. Le Hecho, M. Hassellov, F. Von Der Kammer, M. Potin Gautier, G. Lespes, J. Anal. At. Spectrom. 25 (2010) 613.

[32] U.S. Environmental Protection Agency, EPA/600/R-99/064, 2000, Office of Water, Washington, DC, 20460.

[33] J.F. Ranville, Environmental Effects of Nanoparticles and Nanomaterials, Clemson University, August 21-26, 2010 (Abstract).

[34] A.J. Bednar, A.R. Poda, A.J. Kennedy, A. Harmon, J.F. Ranville, D.M. Mitrano, J.A. Steevens, 31st Annual SETAC North America Meeting, Portland, OR, November $11,2010$.

[35] A.J. Kennedy, M.S. Hull, A.J. Bednar, J.D. Goss, J.A. Steevens, Environ. Sci. Technol. 44 (2010) 9571. 